Nada Bojic - Ruzica Nikolic - Milan Banic - Branislav Hadzima*

\title{
EVALUATION OF MECHANICAL PROPERTIES OF THE TWO PVC CONVEYOR BELTS
}

Conveyor belts with woven plastic belts, aimed for general applications, are very economical transporting means for longer distances. During the operation, the conveyor belts are subjected to various mechanical loadings. The consequences of those loadings are increased stretching of the belt and change of its tensile strength, which negatively affect the proper functioning of the transporter. To avoid the irregularities in the conveyor belt's operation, the tensile properties of the two plastic woven belts were tested (maximal force, maximal extension, breaking force and extension at break). In that way the conditions of the two belts were established. Based on performed experiments the belt that is more suitable for application in the transporter was defined.

Keywords: woven plastic belt, extension, tensile strength, conveyor belt

\section{Introduction}

Modern exploitation technology has determined the importance and role of the continuous transport, especially of the conveyor belts, as their main representatives. Transport by conveyor belts enabled application of the complex technology during the exploitation of various types of the raw materials and achieving the high productivity. Application of the conveyor belts provides for organizing the continuous and completely automated production process.

The bulk materials handling operations are the key functions in a great number of industries. The nature of the handling tasks and scale of their operations vary from one industry to another. However, the relative costs of storing and transporting bulk materials are generally quite significant. Thus, it is important for the transportation systems to be designed and operating in such a manner that the maximum efficiency and reliability are secured [1].

Out of various modes of the bulk solids transporting, the belt conveyors are considered as the most important, mainly due to their widespread use and reliability. Though their use was in the past largely confined to the in-plant transport of materials, they are now dominantly applied in transportation systems for moving various minerals, both in open pits and underground mines, as well.

The belt conveyors can have the load carrying capacity up to $30000 \mathrm{t} / \mathrm{h}$ and can be used for transporting the materials along the large length of conveying paths of up to $3-4 \mathrm{~km}$. They are of relatively simple design, easily maintained and highly reliable in operation. The belt conveyor systems are used in various industries, such as in the foundry shop for supply and distributing the molding sand, molds and removal of waste, in coal and mining industry, sugar industry, agricultural and bagasse industry, fuel industry etc. [2].
These applications are made possible through the development of steel cord conveyor belting and the high potentials for broader applications has appeared due to application of the new lightweight belt materials, which also possess the high strength, like for instance those reinforced with Aramid fibers.

The transport task of the belt conveyors can be defined as a process of transporting the set quantity of the bulk material, within a defined time, between the set uploading and unloading locations. This determines the capacity of the conveyor, as well as the route profile and layout. The conveyor belt designer must select the right belt speed and width and to determine the basic parameters of the conveyor's functioning [3]. The belt conveyors are generally of the modular structure, so the designer has to correctly select the prefabricated subassemblies and combine them into a machine system, which will then execute the set transport task. Today, the modern belt conveyors use the belts that are manufactured by the state-of-the-art technologies. Their drives are equipped by the advanced and complex control systems, while the belt support systems are optimized according to the criteria of cutting the costs and increased durability. The belt conveyors are now accompanied by equipment for tensioning the belt as a function of the conveyor's driving system load.

In the past, the belt conveyor systems were often designed using the static analysis, which was based on manufacturers' handbooks and recommendations or the concurrent design standards. It was generally assumed that they are loaded as in the steady state and the belt tensions were calculated solely based on the drive requirements and the need to limit the belt sag. The unknown dynamic effects and uncertain belt splice efficiencies were "taken into account" through extremely high safety factors of the order of 7:1. However, today the dynamic behavior of belts during the starting, stoppings and operation are being properly considered, what leads to resonance free designs, lower and more realistic safety factors and increased reliability [1].

\footnotetext{
* ${ }^{1}$ Nada Bojic, ${ }^{2,3}$ Ruzica Nikolic, ${ }^{4}$ Milan Banic, ${ }^{2}$ Branislav Hadzima

${ }^{1}$ Factory of Sieves and Bearings "FASIL" A.D., Arilje, Serbia

${ }^{2}$ Research Center, University of Zilina, Slovakia

${ }^{3}$ Faculty of Engineering, University of Kragujevac, Serbia

${ }^{4}$ Faculty of Mechanical Engineering, University of Nis, Serbia

E-mail: ruzicarnikolic@yahoo.com
} 


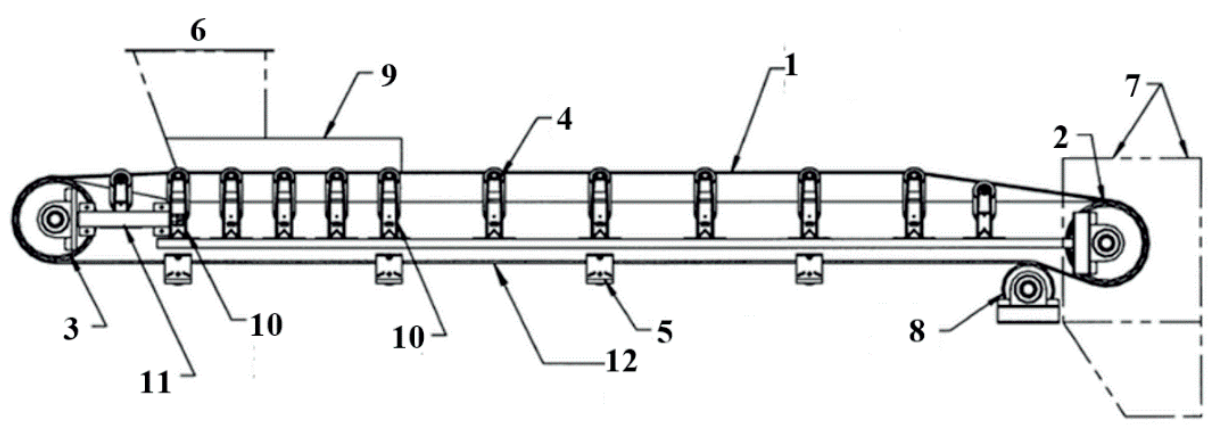

Figure 1 The scheme of the conveyor belt

1 - Troughed conveyor belt; 2 - Head pulley and drive; 3 - Tail pulley; 4 - Troughing carrying idlers; 5 - Return idlers; 6 - Feed chute; 7 - Discharge chute; 8 - Snub pulley; 9 - Loading skirts; 10 - Idlers at loading point; 11 - Horizontal screw take-up; 12 - Stringer (conveyor structure) [9].

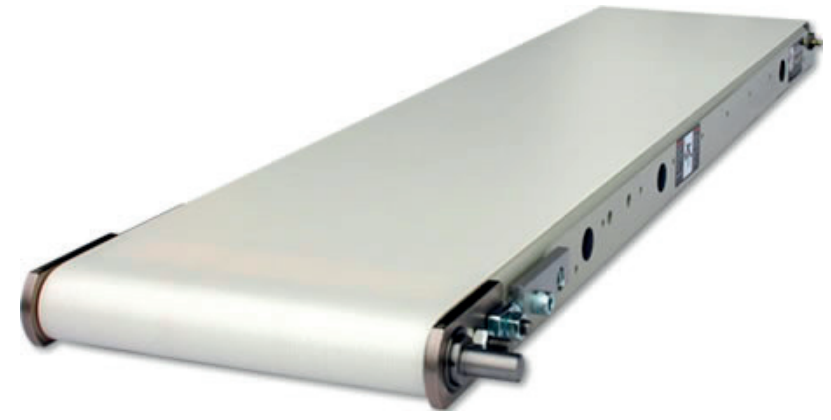

Figure 2 Appearance of the conveyor belt

For instance, the impact process analysis, performed in [4], is based on the hypothesis that the movement of an object, falling onto the conveyor belt and then bouncing on it, is similar to the damped harmonic motion. This is done since the detailed examination of conveyor belts in practice indicated a strong influence of the wear and damage, caused by the dynamic and impact loading, on the conveyor belt service life.

During the conveyor belt operation, the belt is gradually worn out and damaged as a result of deterministic and stochastic stresses, which may not act simultaneously, but in certain time intervals. The risk factors include the multiaxial impact compressive stress, bending and shear stresses, caused by the impact forces, producing wear of the cover layers and often even punctures of the entire conveyor belt. The economic significance of the costs caused by the wear is enormous.

In [5] authors were analyzing the failure of the textile rubber conveyor belt damaged by the dynamic wear. During the operation, the conveyor belt is exposed to working conditions, which are causing the wear and/or damage. The wear on conveyor belts is characterized by almost evenly distributed abrasion of the covers and by the local damage, like tears, nicks in the cover, penetration of the belt and longitudinal slitting. The conveyor belting is the most exposed to damage at the loading station. The objective of that research was to obtain knowledge about the damage process, which is required for the correct regulation of the conveyor belt's operation conditions. The aim was to determine the conditions that caused this type of damages - the height of the material pieces impact and their weight. They used the nondestructive method of the computer metro-tomography to study the changes in the construction of the conveyor belt.
Authors of [6] presented experimental measurements of selected properties of the pipe conveyor belts, which were dynamically damaged. The "popularity" of the pipe conveyors lies in their ability to ensure the protection of environment through which they are passing. They are also proven to be the cost-effective, producing the low labor and operating costs. The pipe conveyors can overcome the problems like integration into the existing industrial system, limited or obstructed space and a difficult terrain. The essential design feature of the pipe conveyors is their tubular shape that is more stable over the straight distances when it comes to belt operation/torsion.

The plastic conveyor belts are elastic and flexible and can be used for various types of transport of the bulk materials, both horizontally or inclined [7]. The conveyor belts importance is often neglected, since they are usually planned as the part of the manufacturing equipment that does not cause any problems and can operate without failures for long times [8]. The best method to determine the state of the belt is to control its stretching (extension) and the tensile strength. This would guarantee that the conveyor belt is fully operational to properly execute the task in the manufacturing process. The conveyor belt transporter consists of the driving element, clutch and axle, electromotor and the belt. Figure 1 presents the scheme of the conveyor belt and its actual appearance is shown in Figure 2. The material discharge is done into the discharge chute at the transporter's head.

The objective of this paper was to establish the state of the two plastic woven belts of the transporter system from the aspect of the mechanical properties reliability and to determine which one is more suitable for application in the particular conveyor belt transporter. 


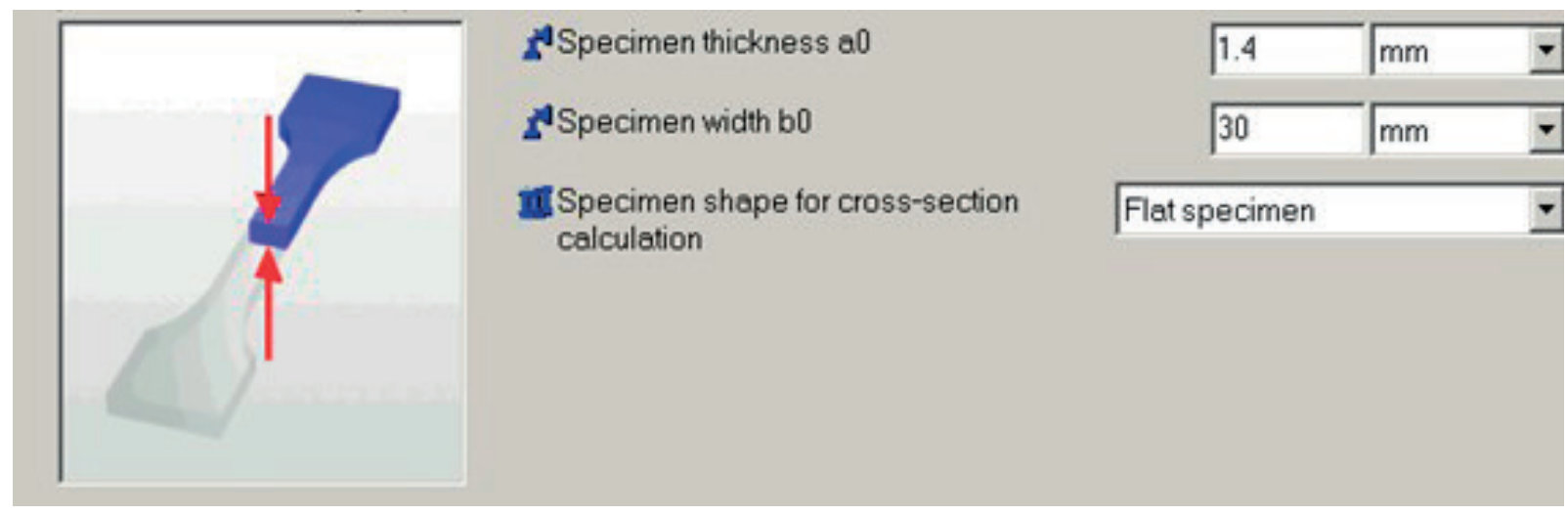

Figure 3 Geometry of the plastic belts' samples

Table 1 Construction of the sieve made from $22 B Y$

\begin{tabular}{ccc}
\hline & Number & 18 \\
Base wire & Diameter & $0.36 \times 0.67$ \\
& Material & Hydrolysis-resistant polyester \\
Weft wire - sieve's face & Number & 7.5 \\
& Diameter & 0.50 \\
\hline Weft wire - sieve's back & Material & Hydrolysis-resistant polyester \\
& Number & 7.5 \\
\hline
\end{tabular}

Table 2 Construction of the sieve made from $31 B Y$

\begin{tabular}{|c|c|c|c|}
\hline & Number & 9 & $/ \mathrm{cm}$ \\
\hline \multirow[t]{3}{*}{ Base wire } & Diameter & $0.36 \times 0.67$ & $m m$ \\
\hline & Material & Hydrolysis-resistant polyester & \\
\hline & Number & 9 & $/ \mathrm{cm}$ \\
\hline \multirow[t]{3}{*}{ Weft wire - sieve's face } & Diameter & $0.36 \times 0.67$ & $m m$ \\
\hline & Material & Hydrolysis-resistant polyester & \\
\hline & Number & 6.4 & $/ \mathrm{cm}$ \\
\hline \multirow[t]{2}{*}{ Weft wire - sieve's back } & Diameter & 0.70 and 0.80 & $m m$ \\
\hline & Material & Hydrolysis-resistant polyester & \\
\hline
\end{tabular}

\section{Transporting belt}

The basic and the most important part of the conveyor belt is the endless belt, made of the steel sieve, which is carrying the load. The belt is usually the most expensive part of the transporting system. The belts can be made of different materials, depending on the needs and requirements of the buyer. The usual materials are rubber, textile, steel tape, steels sieve covered by the woven plastic tape, etc. The belt is being driven over at least two rollers, one driving and one tightening, which are placed at the ends of the carrying structure. The transporting distance is defined by the axial distance between those two rollers. The belt, both the top (carrying) and the return (pulley) portion, is supported by the regularly placed idlers. As can be seen from Figure 1, in the loading section there are larger number of the closely spaced idlers, which must accept the incoming impact load on the belt.

The belt must fulfill several conditions to be fully operationalto be flexible, to have certain tensile strength and to be resistant to impact and wear. The subject of this research was the plastic belt (sieve), which transports the sawdust. The sieve represents an intertwined wire, which is formed by weaving of the two sets of wires, namely alternative weaving of the base wire and the weft wire, at a right angle. The base wires are parallel to the motion direction of the sieve (belt) and the weft wires are perpendicular to them [10], [11], [12]. The inner dimensions of the sieve represent the combination of the wire diameters and their distances; the opening between the wires is called the "eyelet". The variables that make the inner dimensions of the sieve are the wire diameter $(\mathrm{mm})$, the opening size, the step, number of wires per $\mathrm{cm}$ and the illuminated-through area.

The belts are being delivered in different sizes, widths and lengths. They can be delivered as connected or the connecting can be done directly on the conveyor. For the plastic belt, the cover is made of the PVC, polyamide or some other plastics [13]. The plastic belts are resistant to humidity, oils, grease, chemicals and sea-water. They are manufactured in standardized widths 
from 200 to $4500 \mathrm{~mm}$. In the case of the bulk material with larger pieces, the belt width must be expressed as a function of the piece's largest dimension $\left(a_{\max }\right)$ as

$B \geq 3 a_{\max }+0.2 m$

where: $B$ - is the belt's width.

In the case of the piece load, the belt's width calculation is done according to:

$$
B \geq a_{\max }+0.2 m
$$

where $a_{\max }$ is the size of the largest piece.

\section{Experimental setup}

Two experiments were performed on samples from the two types of woven plastic belts, $22 \mathrm{BY}$ and 31BY. The data for constructions of sieves made from these two plastic materials are given in Table 1 and Table 2. Their geometry is shown in Figure 3.

Tests were executed in Laboratory for Mechanical testing in Factory "FASIL". The universal testing machine ZWICK ROELL Z100 was used for tensile test, with recordings of the load and extension. One of the hydraulic jaws was serving for the sample fastening, connected to the fixed part of the machine, while the other was connected to the moving part. The hydraulic jaws were so fixed that when the load changes they would automatically take the position in such a way that the longitudinal axis of the sample coincides with the machine axis. The maximum distance between the jaws was $590 \mathrm{~mm}$. The sample was properly fixed so no slippage from the jaws would occur during the tension. The mechanism was without inertia at the prescribed test rate. The recorded extension had accuracy of $1 \%$. The maximum tensile force was $10000 \mathrm{~N}$. During the test, the maximum distance between the hydraulic jaws was $150 \mathrm{~mm}$. The tension rate was 400 $\mathrm{mm} / \mathrm{min}$. The test rate was $20 \mathrm{~mm} / \mathrm{min}$.

The parameters of the conveyor belt transporter, for which the belts were tested, were the following: transporting distance $295 \mathrm{~m}$, efficiency $145 \mathrm{t} / \mathrm{h}$, the transported material cross-section

Example 1. Belt type 22BY: $\mathrm{N}_{\mathrm{b}}=18 \mathrm{~N}_{\mathrm{w}}=7.5$

( $\mathrm{N}_{\mathrm{b}}$ is the number of the base and $\mathrm{N}_{\mathrm{w}}$ is the number of the weft)

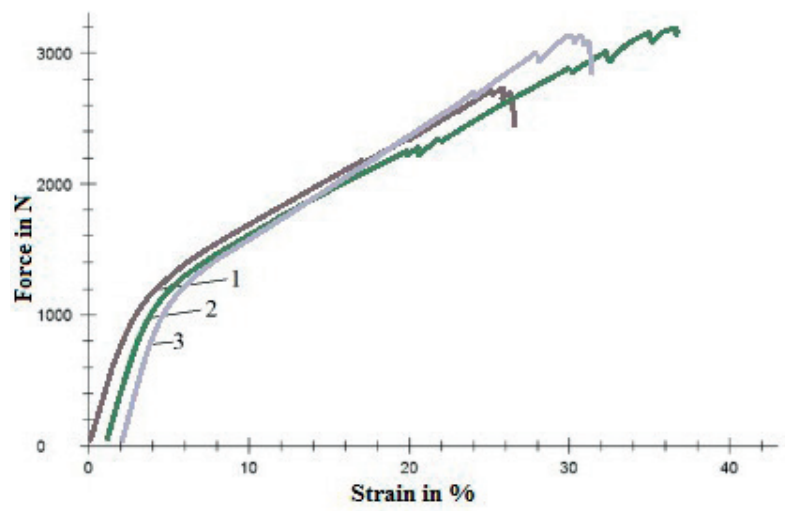

Figure 4 Force - strain diagram for the belt type 22BY sample
$0.0105 \mathrm{~m}^{2}$, the driving pulley diameter $60 \mathrm{~mm}$, driving rpms 45 $\mathrm{min}^{-1}$, engine power $40 \mathrm{~kW}$, puling force on the driving pulley perimeter $13.025 \mathrm{~N}$.

\section{Results and discussion}

Results of experiments are presented in Figure 4 and Figure 5 and in Table 3 and Table 4. The variables in tables are:

$a_{0}$ - sieve's sample thickness

$b_{0}$ - sieve's sample width

$L_{0}$ - sieve's sample length

$F_{\text {max }}$ - maximal force

$F_{\text {Break }}$ - breaking force

$\varepsilon_{\text {Break }}$ - extension at break

$\varepsilon_{\text {Fmax }}$ - maximal extension.

\section{Conclusions}

- Based on the conducted tests, it was established that the woven plastic belt of the 22BY type has the lower extension in $\%$ and the higher breaking force, with respect to the plastic belt of the 31BY type. Allowed extension of the sieve for this application is $33 \%$. Extensions of $25.78 \%$ and $28.02 \%$ will not lead to increased friction between the carrying idler and the belt, thus, it will not cause the conveyor belt wear.

- Obtained results do not exceed the limit values of 2550 -3300 $N$, so it is concluded that the additional maintaining system need not to be activated. These values are provided by the belts manufacturer. The characteristics of the 22BY belt is the air permeability of $125 \mathrm{~Pa}$ at $350 \mathrm{CFM}$ and at $100 \mathrm{~Pa}-5700$ $\mathrm{m}^{3} / \mathrm{m}^{2} / \mathrm{h}$, what additionally increases elasticity of this belt and thus extends its applications field, as well. The 22BY belts enable application in various industrial processes, since due to their construction and characteristics they possess high reliability and long exploitation life.

- "A Conveyor is only as good as the belt that's on it" [14].

Example 2. Belt type 31BY: $\mathrm{Nb}=9 \mathrm{Nw}=9$

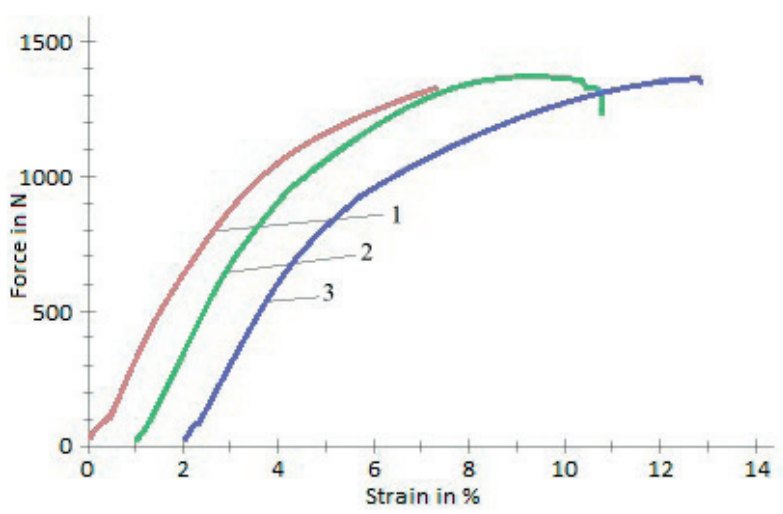

Figure 5 Force - strain diagram for the belt type 31BY sample 
Table 3 Results of the tensile test for the belt type 22BY sample

\begin{tabular}{|c|c|c|c|c|c|c|c|}
\hline No. & $\begin{array}{c}a_{0} \\
\mathrm{~mm}\end{array}$ & $\begin{array}{c}b_{0} \\
\mathrm{~mm}\end{array}$ & $\begin{array}{c}L_{0} \\
\mathrm{~mm}\end{array}$ & $\begin{array}{c}F_{\max } \\
\mathrm{N}\end{array}$ & $\begin{array}{c}F_{\text {Break }} \\
\mathrm{N}\end{array}$ & $\begin{array}{c}e_{\text {Break }} \\
\%\end{array}$ & $\begin{array}{c}e_{\mathrm{Fmax}} \\
\%\end{array}$ \\
\hline 1 & 1.4 & 30 & 150.46 & 2732.42 & 2439.67 & 26.58 & 25.78 \\
\hline 2 & 1.4 & 30 & 150.49 & 3189.34 & 3127.55 & 35.72 & 35.68 \\
\hline 3 & 1.4 & 30 & 150.50 & 3143.50 & 2827.67 & 29.48 & 28.02 \\
\hline
\end{tabular}

Table 4 Results of the tensile test for the belt type $31 B Y$ sample

\begin{tabular}{|c|c|c|c|c|c|c|c|}
\hline No & $\begin{array}{c}a_{0} \\
\mathrm{~mm}\end{array}$ & $\begin{array}{c}b_{0} \\
\mathrm{~mm}\end{array}$ & $\begin{array}{c}L_{0} \\
\mathrm{~mm}\end{array}$ & $\begin{array}{c}F_{\max } \\
\mathrm{N}\end{array}$ & $\begin{array}{c}F_{\text {Break }} \\
\mathrm{N}\end{array}$ & $\begin{array}{c}e_{\text {Break }} \\
\%\end{array}$ & $\begin{array}{c}e_{\mathrm{Fmax}} \\
\%\end{array}$ \\
\hline 1 & 1.5 & 30 & 150.45 & 1328.46 & 1326.36 & 7.32 & 7.27 \\
\hline 2 & 1.5 & 30 & 150.33 & 1373.56 & 1229.47 & 9.80 & 8.68 \\
\hline 3 & 1.5 & 30 & 150.32 & 1369.63 & 1350.36 & 10.86 & 10.73 \\
\hline
\end{tabular}

\section{Acknowledgement}

This research was financially supported by European regional development fund and Slovak state budget by the project "Research Centre of the University of Zilina" and by the Ministry of Education, Science and Technological Development of Republic of Serbia through grant TR 35024.

\section{References}

[1] ROBERTS, A. W., HARRISON, A.: Recent Research in Belt Conveyor Technology. Proceedings of the "Belcon 5", 1-24, 1989.

[2] MANE, S. P, MANE, P. A., HARAGE, C. G., PRAJAPATI, R. R.: Trials and Analysis on Belt System used for Cooling of casting Mould. International Journal of Current Engineering and Technology, 5(2), 762-767, 2015.

[3] KULINOWSKI, P.: Simulation Studies as the Part of an Integrated Design Process Dealing with Belt Conveyor Operation. Maintenance and Reliability, 15(1), 83-88, 2013.

[4] GRINCOVA, A., ANDREJIOVA, M., MARASOVA, D.: Failure Analysis of Conveyor Belt in Terms of Impact Loading by Means of the Damping Coefficient. Engineering Failure Analysis, 68, 210-221, 2016.https://doi.org/10.1016/j.engfailanal.2016.06.006

[5] FEDORENKO, G., MOLNAR, V., GRINCOVA, A., DOVICA, M., TOTH, T., HUSAKOVA, N., TARABA, V., KELEMEN, M.: Failure Analysis of Irreversible Changes in the Construction of Rubber-Textile Conveyor Belt Damaged by Sharp-Edge Material Impact. Engineering Failure Analysis, 39, 135-148, 2014.https://doi.org/10.1016/j.engfailanal.2014.01.022

[6] FEDORENKO, G., MOLNAR, V., ZIVCAK, J., DOVICA, M., HUSAKOVA, N.: Failure Analysis of Textile Rubber Conveyor Belt Damaged by Dynamic Wear. Engineering Failure Analysis, 28, 103-114, 2013.https://doi.org/10.1016/j.engfailanal. 2012.10.014

[7] TOLMAC, D., PRVULOVIC, S.: Transportation Systems(In Serbian). University of Novi Sad, Technical Faculty in Zrenjanin, 2012.

[8] DROBNJaKoviC, B., MilAnOVIC, D., DROBNJAKOVIC, V.: Selection of a Belt Feeder Drive Group of Crushing Plant for Ore/Waste at the Open Pit of Veliki Krivelj Mine. Mining Engineering, 6(1), 133-138, 2012.https://doi.org/10.5937/ rudrad1201133D

[9] High Speed Conveyor Systems[online]. Available: http://essexengineering.com/parts-conveyor-section-9.html [accessed 2018-0403].

[10] Bojic, N. V., Nikolic, R. R., Jugovic, B. Z., Jugovic, Z. S., Gvozdenovic, M. M.: Uniaxial Tension of Drying Sieves. Chemical Industry, 67(4), 655-662, 2013.

[11] BOJIC, N., JUGOVIC, Z., DRAGICEVIC, S., SLAVKOVIC, R.: Comparative Study of the Tensile Stress of Diagonal Sieves Produced by Plasma Welding and Hard Soldering Process. Metalurgia International, 17(5), 25-29, 2012.

[12] BOJIC, N., JUGOVIC, Z., NIKOLIC, R., LAZIC, V., CUKIC, R.: Determination of Optimal Way for the Diagonal Sieves Joining. Proceedings of "IRMES-2011", Serbia, 573-578, 2011.

[13] Fenner-Dunlop: Conveyor Handbook. Conveyor Belting, Australia, 2009.

[14] Bastian Solutions [online]. Available: https://www.bastiansolutions.com [accessed 2018-02-18]. 